\title{
Do Altimeter Wavenumber Spectra Agree with the Interior or Surface Quasigeostrophic Theory?
}

\author{
P.Y. Le Traon ${ }^{1,{ }^{*}}$ P. Klein ${ }^{1}$, Bach Lien Hua ${ }^{1}$ and G. Dibarboure ${ }^{2}$ \\ ${ }^{1}$ Ifremer, Centre de Brest, 29280 Plouzané, France \\ ${ }^{2}$ CLS Space Oceanography Division, 8-10 rue Hermès, 31526 Ramonville St Agne, France \\ *: Corresponding author : P.Y. Le Traon, email address : Pierre.Yves.Le.Traon@ifremer.fr
}

\begin{abstract}
:
In high-eddy-energy regions, it is generally assumed that sea level wavenumber spectra compare well with quasigeostrophic (QG) turbulence models and that spectral slopes are close to the expected k-5 law. This issue is revisited here. Sea level wavenumber spectra in the Gulf Stream, Kuroshio, and Agulhas regions are estimated using the most recent altimeter datasets [the Ocean Topography Experiment (TOPEX)/Poseidon, Jason-1, the Environmental Satellite (Envisat), and the Geosat Follow-On]. The authors show that spectral slopes in the mesoscale band are significantly different from a k-5 law, in disagreement with the QG turbulence theory. However, they very closely follow a $k-11 / 3$ slope, which indicates that the surface quasigeostrophic theory (SQG) is a much better dynamical framework than the QG turbulence theory to describe the ocean surface dynamics. Because of the specific properties of the SQG theory, these results offer new perspectives for the analysis and interpretation of satellite data.
\end{abstract}




\section{Introduction}

Over the past 15 years, five different altimeter missions have been providing high resolution alongtrack sea surface height (SSH) (i.e. sea level) measurements: ERS-1/2 (1991-2003), TOPEX/Poseidon (1992-2005), GEOSAT Follow On (2000-2006), ENVISAT and Jason-1 (20022006). The along-track resolution of altimeter measurements (for 1 second average) is approximately $7 \mathrm{~km}$ but the altimeter noise level (2 to $3 \mathrm{~cm}$ rms) limits the ability to observe along-track wavelengths smaller than approximately 30 to $70 \mathrm{~km}$ (the exact value depends on geographical area and the altimeter mission) (e.g. Zanife et al., 2003; Faugère et al., 2006). Still, this resolves most of the midlatitude mesoscale signals whose wavelengths are typically comprised between 50 and $500 \mathrm{~km}$.

Satellite altimetry is ideally suited to the statistical characterization of mesoscale variability thanks to its global, repeat and long-term sampling of the ocean. The estimation of sea surface height (SSH) wavenumber spectra is, in particular, a unique contribution of satellite altimetry. Following the pioneering work of Fu (1983) with Seasat data, a detailed analysis was conducted, in particular, by Le Traon et al. (1990) with GEOSAT data and by Stammer (1997) with TOPEX/Poseidon data. In high eddy energy regions, where eddies are mainly generated through baroclinic instability and the dynamics are highly non-linear, altimeter wavenumber slopes follow a law close to $\mathrm{k}^{-4}$ for a scale range from 50-100 km up to a spectral peak that generally emerges at twice the wavelength of the internal deformation radius (i.e. $300-400 \mathrm{~km}$ at mid-latitudes).

The dynamical explanation of these spectral slopes (see Stammer, 1997) usually invokes the properties of QG turbulence theory (Charney, 1971; Hua and Haidvogel, 1986; McWilliams, 1989). Smith and Vallis (2001), using the QG theory, furthermore argue that the ocean surface dynamics is essentially captured by the first baroclinic mode. However, such explanation does not seem fully satisfactory. Indeed, the observed spectrum $\mathrm{k}^{-4}$ slopes (Le Traon et al., 1990) are weaker than the $\mathrm{k}^{-5}$ law expected from QG turbulence. Furthermore, experimental results from Scott and Wang (2005) (using altimeter data), that exhibit a clear inverse kinetic energy (KE) cascade from the first Rossby radius of deformation to larger scales, does not exactly match the Smith and Vallis (2001) QG interpretation: the latter indeed should imply a direct surface KE cascade (from large scales to the first Rossby radius of deformation) since an inverse cascade is predicted for the barotropic mode only.

An alternate dynamical explanation, based on the SQG theory (Blumen, 1978; Held et al., 1995), has been recently revisited to describe the dynamics of the upper oceanic layers (Lapeyre and Klein, 2006a; LaCasce and Mahadevan, 2006; Isern et al., 2006). SQG theory has been originally proposed by Blumen (1978) as a more appropriate framework to describe the dynamics of boundaries (such as the upper oceanic layers or the upper troposphere) than QG theory. Resulting dynamics is entirely driven by the density evolution on the boundary. As such SQG theory serves as a counterpart to the QG turbulence theory whose properties are intrinsically not appreciably influenced by boundary contrasts (Blumen, 1978). SQG theory implies a SSH spectrum slope in $\mathrm{k}^{-11 / 3}$ (Blumen, 1978; Held et al., 1995), i.e. quite different from the $\mathrm{k}^{-5}$ law of QG turbulence, and furthermore involves an inverse KE cascade (Capet et al., 2007b).

Which dynamical explanation, QG or SQG, is pertinent to describe the SSH variability and, more precisely, are the wavenumber spectrum slopes closer to the $\mathrm{k}^{-5}$ law or to the $\mathrm{k}^{-11 / 3}$ law ? To address this question, we precisely recalculate wavenumber spectral slopes in high eddy energy regions using the most recent altimeter data sets. The resulting spectral slopes significantly differ from a ${ }^{-5}$ law and therefore disagree with QG turbulence theory. They are close to the $k^{-11 / 3}$ law and as such favor the SQG theory as a much better dynamical framework to describe the ocean surface dynamics. The note is organized as follows. Section 2 deals with the estimation of spectral slope and its associated error from different altimeter missions. Interpretation of wavenumber spectra and implications are discussed in section 3 . Main results and perspectives are summarized in the conclusion. 


\section{Altimeter wavenumber spectra in high eddy energy regions}

We used TOPEX/Poseidon, Jason-1, GEOSAT Follow On and ENVISAT altimeter data to precisely estimate the $\mathrm{SSH}$ wavenumber spectral slope in the mesoscale band. Three $10^{\circ}$ (in latitude) by $20^{\circ}$ (in longitude) areas corresponding to the three highest eddy energy regions in the world ocean were selected: Gulf Stream, Kuroshio and Agulhas regions. Wavenumber spectra were calculated over a four year period (2002-2005) ${ }^{1}$ as explained in Le Traon et al. (1990) or Stammer (1997). We used here SSH data corrected from all altimeter errors and from a precise mean sea surface to remove the geoid signal. Note that SSH data were not interpolated on a regular along-track grid and that the along-track sampling is not exactly the same for the different missions (it varies between 5.8 and 7.5 $\mathrm{km}$ ). Figures $1 \mathrm{a}, 1 \mathrm{~b}$ and $1 \mathrm{c}$ show the wavenumber spectra for the three regions and for the four different altimeter missions. Slopes were calculated by a least square regression for wavelengths between $100 \mathrm{~km}$ and $300 \mathrm{~km}$. Results are given in table 1 . In this range of wavelengths, the spectral shape in log-log is very close to a straight line. The $100 \mathrm{~km}$ wavelength is above the shorter wavelengths affected by altimeter noise. The $300 \mathrm{~km}$ wavelength is close to and smaller than the wavenumber spectral peak which is about twice the internal Rossby radius (IR) wavelength (i.e. $2 \pi$ times IR) (IR for the three regions is comprised between 30 and $40 \mathrm{~km}$, see Chelton et al., 1997). Formal errors on the spectral slope estimations were also derived as explained in the appendix.

Spectral slopes for the three areas and for the four different altimeters are summarized in table 1 . All these results are remarkably consistent to within $+/-0.1$. The slopes are comprised between -3.4 and -3.7 with a mean value of -3.6 (i.e. very close to $-11 / 3$ ). The formal error on the spectral slope estimations is about 0.1 , i.e. the differences of slopes between regions and altimeters are probably not statistically significant. The slight $(<0.1)$ differences between regions and altimeter missions could, however, also reflect actual small differences in spectral shapes or small anisotropy effects. Note that using smaller $(100-200 \mathrm{~km})$ or larger $(100-400 \mathrm{~km})$ wavelength ranges had only a minor $(+/-0.1)$ impact on the spectral slope estimations.

These calculations indicate that in high eddy energy regions, SSH (resp. velocity) spectral slopes very significantly differ from a $k^{-5}$ law (resp. $\mathrm{k}^{-3}$ ) and rather closely follow a $\mathrm{k}^{-11 / 3}$ (resp. $\mathrm{k}^{-5 / 3}$ ) law. This is clearly in disagreement with QG turbulence theory (Hua and Haidvogel, 1986; McWilliams, 1989) but on the other hand is very close to what the SQG theory predicts (Blumen, 1978; Held et al., 1995). Such result is quite robust given the consistency and small formal errors of our slope estimations. Interpretation and implications of these results are given in the next section.

\section{Implications of SSH wavenumber spectra with $\mathrm{a} \mathrm{k}^{-11 / 3}$ slope}

Recent theoretical and high-resolution numerical studies (that couple both the ocean interior and surface dynamics) have also pointed out the dominance of SQG in the upper layers. Lapeyre and Klein (2006a), using the invertibility principle of potential vorticity, show that the ocean dynamics can be decomposed in terms of a QG solution (forced by the potential vorticity in the interior) and a SQG solution (forced by the near-surface density). They demonstrate the dominance of the SQG dynamics in the upper oceanic layers (down to $300 \mathrm{~m}$ ) for horizontal scales extending from $\mathrm{O}(10 \mathrm{~km})$ to $\mathrm{O}(300-$ $400 \mathrm{~km}$ ). Larger scales near the surface are principally captured by the QG solution. Such relevance of SQG theory for the upper oceanic layers has been confirmed and strengthened by high-resolution simulations using primitive equation models (Capet et al., 2007a; Klein et al., 2007). These simulations reveal a surface velocity spectrum with a $k-5 / 3$ slope for the same horizontal scale range as well as a significant inverse KE cascade extending from scales larger than the first Rossby radius of deformation to the small-scale range (smaller than the Rossby radius of deformation) contrary to the QG theory. At depth larger than 400 m, the velocity spectral properties differ, exhibiting a k-3.5 slope, i.e. close to QG theory. Very similar results, related to the horizontal scale range, the KE spectrum and the inverse cascade, have been also found with high resolution simulations using a SQG model instead of a primitive equation model (Capet et al., 2007b).

\footnotetext{
${ }^{1}$ Over this time period, 3.5 years of data are available for T/P, Jason and GFO and 2.8 years for ENVISAT.
} 
These theoretical and numerical studies are in very close agreement with the experimental results of section 2. Consequently, they strongly suggest that the interpretation in terms of SQG dynamics, in section 2, of SSH variability (that concerns a scale range between $300 \mathrm{~km}$ and $100 \mathrm{~km}$, since smaller scales are not so well resolved by altimeter data) can be extended to scales down to $\mathrm{O}(10 \mathrm{~km})$.

Implication of this extension of SQG properties to small scales is that these scales are dynamically more important than previously thought (when using QG arguments). The reason is that in SQG theory, dynamics is principally driven by the near-surface density (Blumen, 1978) and the resulting production of the small-scale density structures is not restrained by the vertical velocity (zero at the surface) as it is in the interior. One consequence (Held et al., 1995; Hakim et al., 2002) is that these small-scale surface density anomalies are associated to strong relative vorticity values (this is expressed by the $k^{1 / 3}$ vorticity spectrum resulting from the $\mathrm{k}^{-11 / 3} \mathrm{SSH}$ spectrum, that is very different from the $\mathrm{k}^{-1}$ spectrum expected from QG turbulence). Such small-scale vorticity fronts may be unstable (Held et al., 1995), leading to a significant number of small-scale coherent vortices [with a size of $\mathrm{O}(20 \mathrm{~km})]$ that cascade up to larger scales, which eventually affect larger eddies (e.g. Capet et al.,2007a ; Klein et al., 2007). This is what the inverse KE cascade extending down to small scales indicates. Vorticity fronts, such as those associated to filaments [with a O $(10-20 \mathrm{~km})$ width] around the eddies, can also act as dynamical barriers that prevent mixing between the eddies and the far field, which substantially increases their lifetime (Lapeyre et al., 1999). These characteristics mean that any prediction of the upper layer dynamics at mesoscales or larger scales requires some knowledge of these small scales.

A last implication is that these small-scale surface density structures trigger frontogenesis mechanisms and therefore are associated with significant vertical velocity at depth as large of 200$300 \mathrm{~m}$ (Hakim et al., 2002; Lapeyre and Klein, 2006b). The consequence (revealed by high-resolution simulations using both primitive equation and SQG models) is that, in a turbulent eddy field within a $2000 \mathrm{~km}$ square domain, $50 \%$ of the total vertical velocity field in the first $300 \mathrm{~m}$ below the surface is located outside the mesoscale eddies, more precisely within the elongated filaments between the eddies (Hakim et al., 2002; Lapeyre and Klein, 2006b).

\section{Conclusion}

The characterization of SSH wavenumber spectral slopes in high eddy energy regions has been revisited using the most recent altimeter data sets. We showed that altimeter spectral slopes are significantly different from a $\mathrm{k}^{-5}$ law but follow very closely a $\mathrm{k}^{-11 / 3}$ law, indicating a $\mathrm{k}^{-5 / 3}$ slope for the velocity spectrum. These results that clearly disagree with QG theory are in very good agreement with the SQG theory. They also well agree with recent theoretical results and very high resolution numerical simulations pointing out that SQG dynamics extend from the mesoscale $O(300-400 \mathrm{~km})$ to the small scales $O(10 \mathrm{~km})$. Thus SQG turbulence theory appears to be a much more relevant dynamical framework to interpret satellite data. One implication is that the upper ocean dynamics is controlled by both large and small-scale structures, which highlights the additional need to have access to these small scales to reconstruct the total flow in the upper layers. This strongly advocates the need for future very high resolution altimeter systems.

Note that the SQG interpretation is also invoked for the dynamics of the upper troposphere and the tropopause (Juckes, 1994; Hakim et al., 2002; Scott, 2006; Tulloch and Smith, 2006). Tulloch and Smith (2006) use this dynamical argument to explain the $k^{-5 / 3}$ velocity spectrum slope observed near the atmospheric tropopause from the GASP dataset, that concerns a similar scale range (between 600 $\mathrm{km}$ and $10 \mathrm{~km})$.

Because of the specific properties of SQG dynamics (e.g. Hakim et al., 2002 and Lapeyre et al., 2006a), these results stimulate new perspectives for the interpretation of satellite data. One of these properties is that, not only the $2 \mathrm{D}$ horizontal motions, but also the vertical velocity field within the first $300 \mathrm{~m}$ below the surface can be retrieved from the SSH (Lapeyre and Klein, 2006a). The other property is the strong spectral relationship between near-surface density and SSH. This means that, when the Sea Surface Temperature (SST) has a spatial variability that resembles that below the mixed-layer, SST measurements from high-resolution satellite infrared images or microwave radiometer may complement altimeter data to retrieve the 3-D circulation at mesoscale and smaller 
scales in the first $300 \mathrm{~m}$ below the surface. From this point of view, recent results from Isern-Fontanet et al. (2006) and LaCasce and Mahadevan (2006) are very encouraging.

\section{Appendix : estimation of wavenumber spectral slope error}

To estimate the error on the spectral slopes, we first estimated the error on the spectral estimation $\mathrm{S}(\mathrm{k}) . \mathrm{S}(\mathrm{k}) / \mathrm{E}[\mathrm{S}(\mathrm{k})]$, where $\mathrm{E}$ stands for mathematical expectation, follows a $\chi^{2}(2 \mathrm{~N}) / 2 \mathrm{~N}$ law where $\chi^{2}(2 \mathrm{~N})$ is a Chi-2 function with $2 \mathrm{~N}$ degrees of freedom. $\mathrm{N}$ corresponds to the number of independent spectral estimates. For large $\mathrm{N}, \chi^{2}(2 \mathrm{~N}) / 2 \mathrm{~N}$ is close to a normal law with a mean of 1 and standard deviation of $1 / \sqrt{N}$. The standard deviation of $S(k)$ is thus close to $S(k) / \sqrt{ } \mathrm{N}$. Over the $10^{\circ} \times 20^{\circ}$ areas, the number of spectral estimations (which is equal to the number of tracks times the number of cycles) is about 500 per year. We assumed as in Le Traon et al. (1990) that only tracks separated by more than $300 \mathrm{~km}$ and 30 days would yield independent estimates of the spectrum. This yields about 100 degrees of freedom per area and per year. The error on the slope (standard deviation) was then estimated from the least square regression normal equations taking into account $\mathrm{S}(\mathrm{k})$ errors. For a $10^{\circ} \times 20^{\circ}$ area, the standard deviation of the slope error is thus estimated to be about 0.07 to 0.1 for our 4 year averages (depending on actual altimeter coverage in the area). This shows that spectral slopes can be very precisely derived from altimetry. 


\section{Bibliography}

Blumen, W., 1978: Uniform potential vorticity flow: Part I. Theory of wave interactions and twodimensional turbulence. J. Atmos. Sciences, 35, 774-783.

Capet X., J.C. McWilliams, J. Molemaker and A. Shchepetkin, 2007a: Mesoscale to submesoscale transition in the California current system. Part I: Flow structure and eddy flux. J. Phys. Oceanogr., in press.

Capet X., Klein, P., Hua B.L., G. Lapeyre and J. McWilliams, 2007b: Surface kinetic energy transfer in SQG flows. Submitted to J. Fluid Mech.

Charney, J.G., 1971: Geostrophic turbulence. J. Atmos. Sciences, 28, 1087-1095.

Chelton, D. B., R. A. deSzoeke, M. G. Schlax, K. El Naggar and N. Siwertz, 1998: Geographical variability of the first-baroclinic Rossby radius of deformation. J. Phys. Oceanogr., 28, 433-460.

Faugère, Y.,Dorandeu, J.,Lefevre, F.,Picot, N.,Femenias, P., 2006: Envisat ocean altimetry performance assessment and cross-calibration. Sensors, 6 (3), 100-113.

Fu, L. L., 1983: On the wave number spectrum of oceanic mesoscale variability observed by the SEASAT altimeter. J. Geophys. Res., 88, 4331-4341.

Hakim, G., Snyder, C. and Muraki, D., 2002: A new surface model for cyclone-anticyclone asymmetry. J. Atmos. Sci., 59, 2405-2420.

Held, I.M., R.T. Pierrehumbert, S.T. Garner, and K.L. Swanson, 1995: Surface quasi-geostrophic dynamics. J. Fluid Mech., 282, 1-20.

Hua, B. L., and Haidvogel, D. B., 1986: Numerical simulations of the vertical structure of quasigeostrophic turbulence. J. Atmos. Sci., 43, 2923-2936.

Isern-Fontanet J., B. Chapron, G. Lapeyre and P. Klein, 2006: Potential use of microwave sea surface temperatures for the estimation of ocean currents. Geophys. Res. Lett., 33, L24608, doi:10.1029/2006GL027801.

Juckes, M., 1994: Quasigeostrophic dynamics of the tropopause. J. Atmos. Sci., 51, 2756-2768.

Klein, P., Hua B.L., G. Lapeyre, X. Capet, S. LeGentil and H. Sasaki., 2007: Upper Ocean Dynamics from High 3-D Resolution Simulations. J. Phys. Oceanogr., submitted.

LaCasce, J.H. and Mahadevan, A., 2006: Estimating subsurface horizontal and vertical velocities from sea surface temperature. J. Marine Res., 27, 695-721.

Lapeyre, G., P. Klein and B.L. Hua, 1999: Do tracer gradient vectors align with strain vectors in 2-D flows? Phys. Fluids, 11, 3729-3737.

Lapeyre G. and P. Klein, 2006a: Dynamics of the Upper Oceanic Layers in Terms of Surface Quasigeostrophy Theory. J. Phys. Oceanogr., 36, 2, 165-176.

Lapeyre, G., and P. Klein, 2006b: Impact of the small-scale elongated filaments on the vertical pump. J. Marine. Res., 64, 835-851.

Le Traon, P.Y., Rouquet, M. C., Boissier, C., 1990: Spatial scales of mesoscale variability in the North Atlantic as deduced from GEOSAT data. J. Geophys. Res., 95, 20,267-20,285.

McWilliams, J. C., 1989: Statistical properties of decaying gesotrophic turbulence. J. Fluid Mech., 108, 199-230.

Scott, R.K., 2006: Local and non-local advection of a passive scalar. Phys. Fluids, 18, 122-125.

Scott, R. and Wang, F., 2005: Direct evidence of an oceanic inverse kinetic energy cascade from satellite altimetry. J. Phys. Oceanogr., 35, 1650-1666.

Smith K.S. and G. K. Vallis, 2001: The scales and equilibration of midocean eddies:freely evolving flow. J. Phys. Oceanogr., 31, 554-571.

Stammer, D., 1997: Global characteristics of ocean variability estimated from regional TOPEX/POSEIDON altimeter measurements. J. Phys. Oceanogr,. 27, 1743-1769.

Tulloch, R. and K. S. Smith, 2006: A theory for the atmospheric energy spectrum: Depth-limited temperature anomalies at the tropopause, PNAS, 103, 14690-1469.

Zanife, O. Z., Vincent, P., Amarouche, L.,Dumont, J. P., Thibaut, P., Labroue, S., 2003: Comparison of the Ku-Band range noise level and the relative sea-state bias of the Jason - 1, TOPEX, and Poseidon-1 radar altimeters. Marine Geodesy, 26, 201-238. 


\section{Gulf Stream}

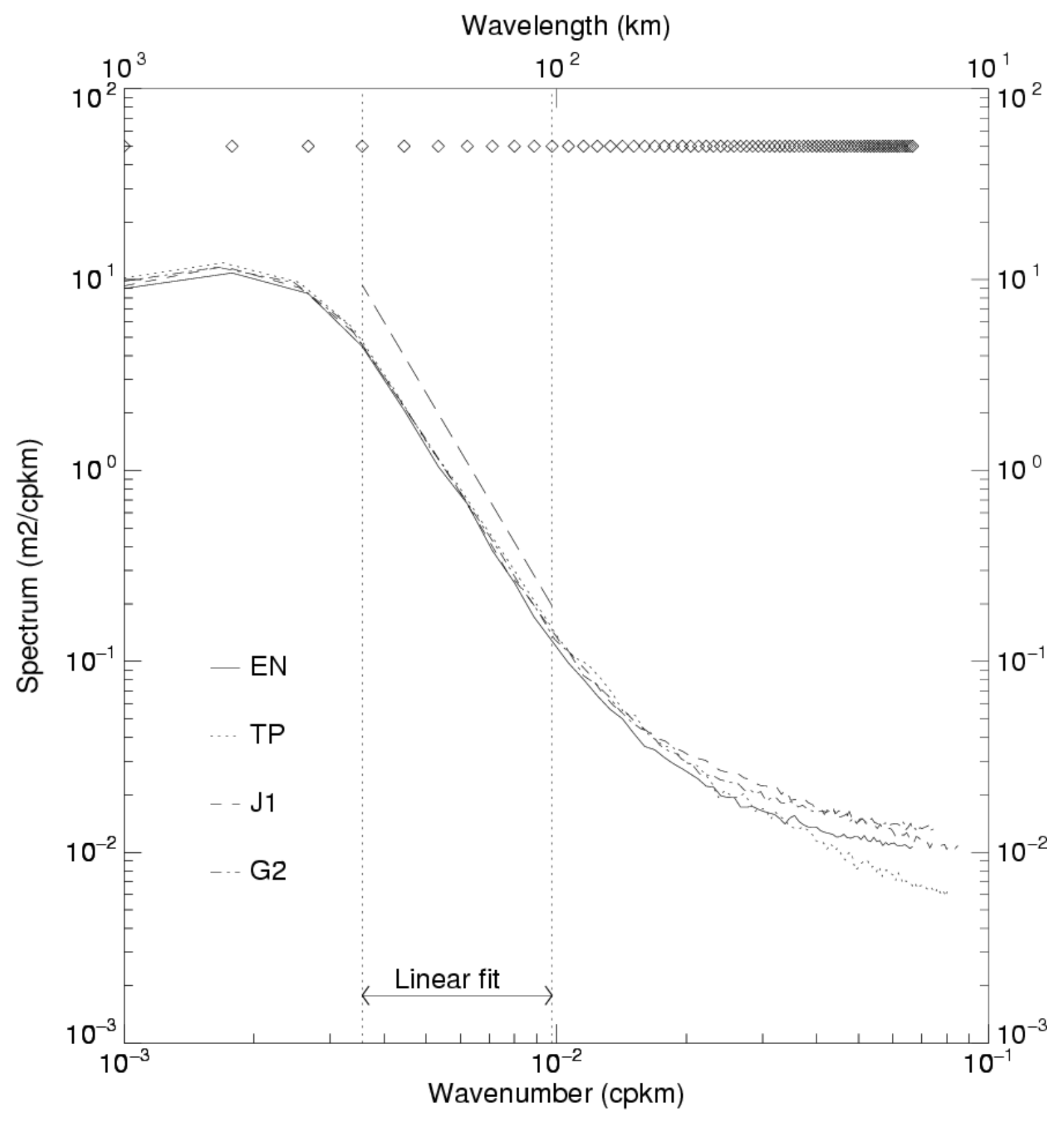

Figure 1a: Along-track altimeter wavenumber spectrum for the Gulf Stream area for TOPEX/Poseidon, Jason-1, ENVISAT and GEOSAT Follow On. Spectral slopes were estimated in the $100 \mathrm{~km}$ to 300 $\mathrm{km}$ spectral band. $\mathrm{A} \mathrm{k}^{-11 / 3}$ slope is also shown (dashed line). 


\section{Kuroshio}

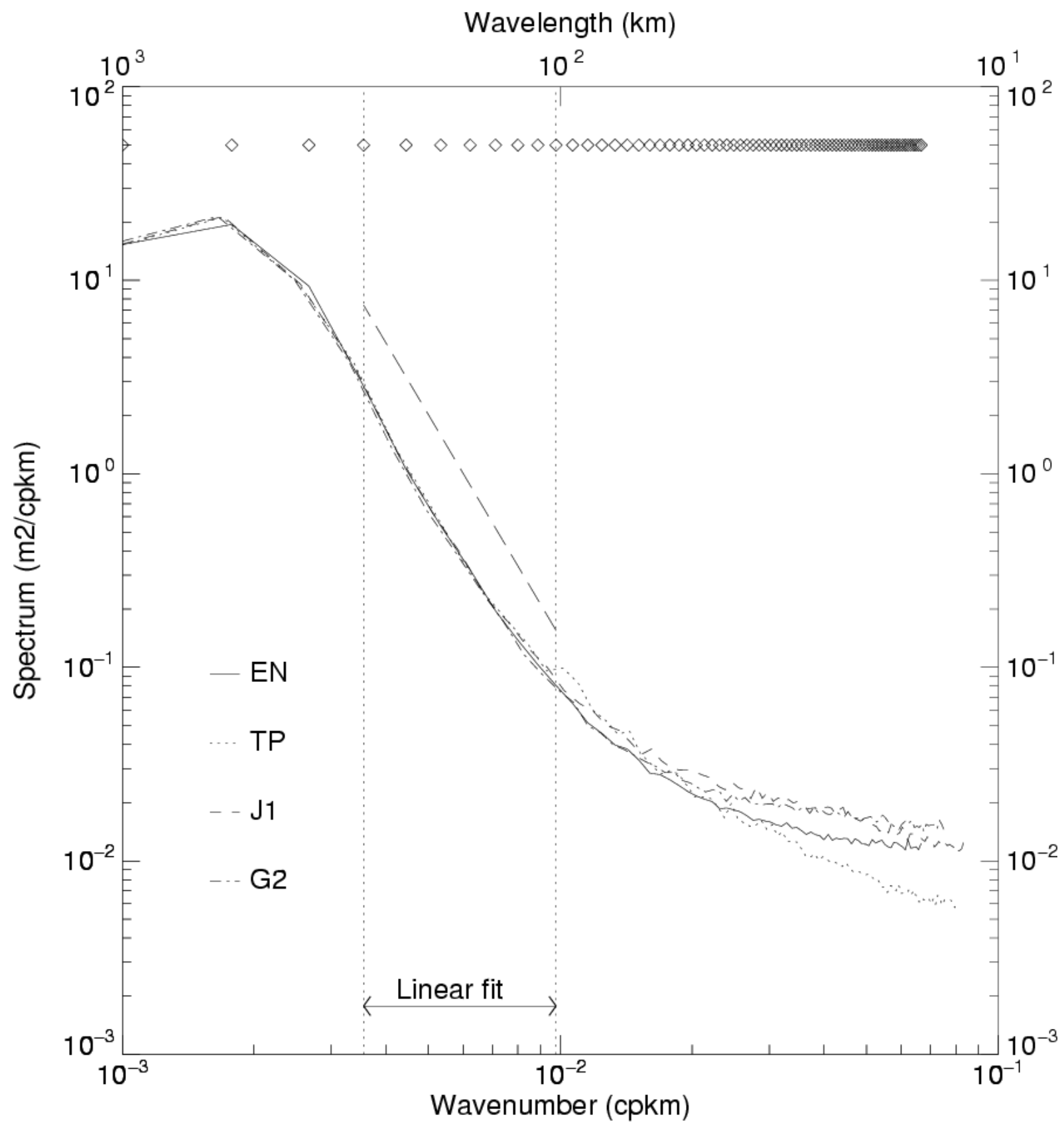

Figure 1b: Along-track altimeter wavenumber spectrum for the Kuroshio area for TOPEX/Poseidon, Jason-1, ENVISAT and GEOSAT Follow On. Spectral slopes were estimated in the $100 \mathrm{~km}$ to 300 $\mathrm{km}$ spectral band. $\mathrm{A} \mathrm{k}^{-11 / 3}$ slope is also shown (dashed line). 


\section{Agulhas}

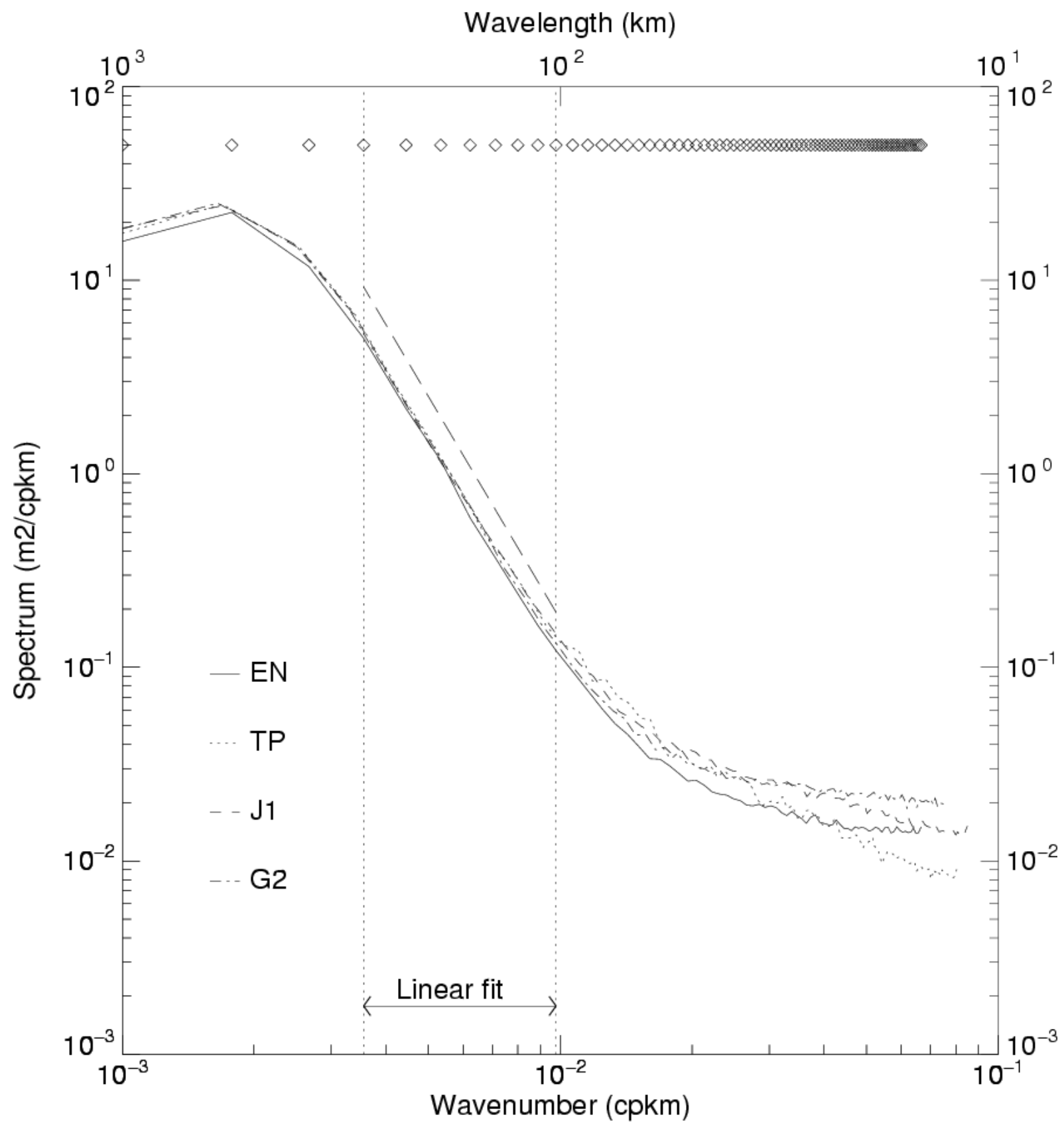

Figure 1c: Along-track altimeter wavenumber spectrum for the Agulhas area for TOPEX/Poseidon, Jason-1, ENVISAT and GEOSAT Follow On. Spectral slopes were estimated in the $100 \mathrm{~km}$ to 300 $\mathrm{km}$ spectral band. $\mathrm{A} \mathrm{k}^{-11 / 3}$ slope is also shown (dashed line). 


\section{Tables}

Table 1: Spectral slope estimations for the three areas. The slopes were estimated from wavenumber spectra for wavelengths comprised between 100 and $300 \mathrm{~km}$ (see figures 1).

\begin{tabular}{|l|l|l|l|l|}
\hline & T/P & Jason-1 & ENVISAT & GFO \\
\hline Gulf Stream & 3.44 & 3.44 & 3.51 & 3.46 \\
\hline Kuroshio & 3.55 & 3.59 & 3.68 & 3.52 \\
\hline Algulhas & 3.70 & 3.69 & 3.72 & 3.71 \\
\hline
\end{tabular}

